\title{
RESEARCH
}

\section{Variation in health services utilization among ethnic populations}

\author{
Hude Quan, Andrew Fong, Carolyn De Coster, Jianli Wang, Richard Musto, Tom W. Noseworthy, \\ William A. Ghali
}

\section{ABSTRACT}

Background: Although racial and ethnic disparities in health services utilization and outcomes have been extensively studied in several countries, this issue has received little attention in Canada. We therefore analyzed data from the 2001 Canadian Community Health Survey to compare the use of health services by members of visible minority groups and nonmembers (white people) in Canada.

Methods: Logistic regression was used to compare physician contacts and hospital admissions during the 12 months before the survey and recent cancer screening tests. Explanatory variables recorded from the survey included visible minority status, sociodemographic factors and health measures.

Results: Respondents included 7057 members of visible minorities and 114255 white people for analysis. After adjustments for sociodemographic and health characteristics, we found that minority members were more likely than white people to have had contact with a general practitioner (adjusted odds ratio [OR] 1.28, 95\% confidence interval [CI] $1.14^{-1.42}$ ), but not specialist physicians (OR 1.01, 95\% Cl $0.93^{-1.10}$ ). Members of visible minorities were less likely to have been admitted to hospital (OR $0.83,95 \% \mathrm{Cl} 0.70-$ 0.98 ), tested for prostate-specific antigen (OR $0.64,95 \% \mathrm{Cl}$ $0.52-0.79$ ), administered a mammogram (OR $0.68,95 \% \mathrm{Cl}$ $0.59-0.80$ ) or given a Pap test (OR $0.47,95 \% \mathrm{Cl} 0.39-0.56$ ).

Interpretation: Use of health services in Canada varies considerably by ethnicity according to type of service. Although there is no evidence that members of visible minorities use general physician and specialist services less often than white people, their utilization of hospital and cancer screening services is significantly less.

CMAJ 2006;174(6):787-9I

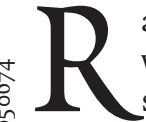

acial and ethnic disparities in the use of health services and in health outcomes have been extensively studied and well documented in the United States and the United Kingdom. Studies from both countries reveal that black, Hispanic and Asian people are less likely to access health care and experience more barriers than people who are not visibly members of ethnic minorities - that is, white people. ${ }^{1-7}$ The factors underlying ethnic disparities in health service usage are complex and could include such variables as health insurance coverage, physicians' attitudes toward minority patients, language, poverty, transportation, education, familiarity with the health care delivery system, and the degree and kind of family support. ${ }^{3,6-17}$

The evidence from the United States and the United Kingdom cannot automatically be generalized to Canada, and there is a need for rigorous study of Canadian ethnic populations and their use of health services. The first reason is that much of the US and UK literature on this topic is broadly categorized into "black" and "Hispanic" populations. The United States, the United Kingdom and Canada have different racial and ethnic population compositions because of historical factors. The legacy of slavery in the United States and of colonization in the United Kingdom have led to a higher proportion of persons identified as black. In contrast, Canada has many Asian people in its ethnic make-up, because in recent years a large proportion of immigrants to Canada have come from Asia (59\%), with a small proportion from Central and South America and the Caribbean (II\%) and Africa (8\%). ${ }^{18}$ At present, the 3 largest visible minority groups in Canada are Chinese (mainly from Hong Kong, Taiwan and mainland China), South Asian (from Asian India, Pakistan, Bangladesh and Sri Lanka) and black people.

The second reason is that culture, health status and sociodemographic characteristics even in the same racial or ethnic population may differ between Canada and the United States or the United Kingdom. In recent years, Canada has selected immigrants with high education, strong technical skills and correspondingly favourable health status, with only a relatively small number of immigrants arriving as refugees; US and UK ethnic minorities may differ in those respects. The third reason is that the Canadian health system differs fundamentally from the US health system, and somewhat from the parallel public and private systems of the United Kingdom. The Canada Health $\mathrm{Act}^{19}$ promises to facilitate reasonable access to health services without financial or other barriers. Residents should therefore have equal access, regardless of ethnic origins. Health services usage patterns by Canadian ethnic populations may therefore have unique features.

In 200I, Statistics Canada conducted the Canadian Community Health Survey (CCHS), ${ }^{20}$ which collected in- 
formation on ethnicity as well as health service utilization from a large sample of Canadians. This study analyzed the national data to assess use of health services by white and visible-minority populations residing in Canada. The findings provide evidence of the degree to which Canada's publicly funded, universal health care system provides equal access to all.

\section{Methods}

Cycle I.I of the CCHS targeted household residents aged I2 years or older in all Canadian provinces and territories. A complex multiple-stage sampling method was used to locate households in 136 health regions across Canada. One respondent per household was randomly selected for telephone interview in any of several languages. ${ }^{20}$ Aboriginal people were excluded from our analysis because the CCHS did not survey people on Indian reserves. White people and members of visible minority groups were included, whether they were immigrants or born in Canada.

The dependent variables included measures of health service utilization: visits to or telephone contact with general practitioners and specialist physicians; hospital admissions during the I2 months before the survey; and receipt of a Pap test, mammogram or prostate-specific antigen (PSA) test at least once. Both Pap testing and mammography are screening tests universally recommended by several authoritative agencies, such as the Canadian Cancer Society; there is less universal endorsement in authoritative guideline statements of PSA testing, but there is nevertheless evidence of reasonably widespread use.

Contact with physicians was obtained by asking "In the past 12 months, how many times have you seen or talked on the telephone about your physical, emotional or mental health with ..." any of a provided list of health care professionals, including "a family doctor or general practitioner; an eye specialist (such as an ophthalmologist or optometrist); and any other medical doctor (such as a surgeon, allergist or orthopedist, gynecologist or psychiatrist)." For this study, we combined the eye and other specialist categories into "specialist physicians." Although the number of contacts in each category was recorded, we dichotomized responses into "zero" or "any."

For hospital admissions, the question was: "In the past I2 months, have you been a patient overnight in a hospital, nursing home or convalescent home?" Use of cancer screening tests was collected by asking women aged I 8 years or older "Have you ever had a Pap smear test?," women aged 35 years or more "Have you ever had a mammogram?" and men aged 40 years or older "Have you ever had a prostate-specific antigen test for prostate cancer, that is, a PSA blood test?"

Ethnicity, the independent variable, was obtained by asking, "People living in Canada come from many different cultural and racial backgrounds. Are you ..." white, Chinese, South Asian (including East Indian, Pakistani or Sri Lankan), black, Latin American, Southeast Asian (Cambodian, Indonesian, Laotian or Vietnamese), West Asian (Afghani or Iran- ian), Japanese, Korean, Filipino, Arab, one of the Aboriginal peoples of North America or "other." Because of small numbers in some groups, we combined data from Filipino respondents with data from Southeast Asian respondents, Arab with West Asian, and Japanese with Korean. Combinations were based on similarities in culture and geography. We defined "white people" as those who described themselves as being white. Data from 239 people (0.20\% of respondents) who described themselves as white and also as having another ethnicity were grouped with white participants who acknowledged no other ethnicity.

Other independent variables included age, sex, marital status, highest level of education attained, total household annual income, number of years in Canada, ability to speak English or French, self-reported general health status and number of chronic health conditions present out of a list of 28 conditions (e.g., food allergies, asthma, arthritis, migraine headache, chronic bronchitis, congestive heart failure, cancer, and stomach or intestinal ulcers).

In our statistical analysis, variables were described with proportions and means across ethnic groups. The sampling weights endorsed by Statistics Canada were used to calculate estimates. To test for differences between white people and members of minorities as a group, we employed $\chi^{2}$ and $t$ test statistics. Stratified analyses were conducted for the potentially important variables of sex, age, income, speaking English or French, and duration of residence in Canada, to determine whether the association between ethnicity and health services utilization varied across strata (effect modification). Logistic regression models were developed to test the association between ethnicity and use of health services before and after adjustment for potential confounding. Because the CCHS used a complex sampling design, we calculated the 95\% confidence intervals (CIs) of odds ratios (ORs) with the bootstrap macros provided by Statistics Canada to account for design effect. ${ }^{20}$

\section{Results}

Of I3I 535 respondents, we excluded data from 3665 native Aboriginal people (2.8\%), I027 responses that lacked ethnicity data (0.8\%) and 553I records (4.2\%) with data missing on other variables. The resulting data set included 7057 people who were members of visible minorities (2III Chinese, 585 Japanese/Korean, I447 South Asian, 973 Filipino/Southeast Asian, $506 \mathrm{Arab} /$ West Asian, Ior6 black and 4I9 Latin American people) and II 255 white people. To adjust for multiple stratified sample design effect, we weighted numbers of respondents using the sample weights provided by Statistics Canada to obtain estimates representative of the ethnicity of the Canadian population. The weighted sample sizes for the 7 grouped ethnicities are those shown in Appendix 1 and Appendix 2, available online (www.cmaj.ca/cgi/content/full/174 /6/787/DCI).

Compared with white people, minority members as a group were significantly younger and more likely to be married, to have achieved secondary or postsecondary education $(74 \%$ v. $71 \%)$ and to have a family income below $\$ 30000$. 
Only $19 \%$ of members of visible minorities were born in Canada; however, $5 \mathrm{I} \%$ of that group had lived in Canada for Io years or longer. Most minority members ( $87 \%$ ) spoke English or French. Fewer members of visible minorities perceived their health as fair or poor than did white people (ro\% v. I $2 \%$ ), or reported having 3 or more chronic diseases. Most of these patterns were repeated within the minority subgroups, with one notable exception: half of those in the Japanese/Korean group were born in Canada.

Appendix 2 shows the use of health services broken down by ethnicity. The proportion of members of visible minorities who had at least one contact with a general practitioner was as high as that of white people. Among visible minorities, Japanese/Korean people used a general practitioner the least and South Asian people, the most (range 70\%-84\%). Members of visible minorities were less likely than white people to have been in contact with specialist physicians or admitted to hospital. The hospital admission rate was even lower among Chinese and Japanese/Korean people (about $4 \%$ ), and highest among Arab/West Asian people ( $>9 \%$ ). Members of visible minorities were less likely than white people to have had a PSA test, mammogram or Pap test.

The disparities between minorities and white people with respect to having contact with a general practitioner or specialist physician, having been admitted to hospital and undergoing cancer screening tests among members of visible minorities were consistent across subgroups by age, sex, income, language and length of residence in Canada (see Appendix 3 and Appendix 4, available online at www.cmaj.ca/cgi/content /full/I74/6/787/DCI).

Table I reveals that, after adjustment for sociodemographic characteristics and health status, members of visible minorities were more likely than white people to have had contact with a general practitioner, equally as likely to have had contact with a specialist physician, and less likely to have been admitted to hospital. They were also less likely to have received any of the 3 cancer screening tests investigated.

\section{Interpretation}

Use of health services in Canada by ethnicity varies considerably according to the type of service. Overall, members of visible minorities' use of the services of specialist physicians was the same as, and of general practitioners even greater than, that by white people - although members of certain visible minorities tended to visit physicians less frequently. The rate of hospital admissions was lower and that of cancer screening tests, markedly lower among members of visible minorities than among white people. These findings suggest that Canadian ethnic residents appear to have equal utilization of physicians but differ in the level of use of hospital and cancer screening services.

Use of health services can be influenced by a combination of system, provider and patient variables. ${ }^{21}$ In this study, one major system variable, insurance coverage, was irrelevant because Canada has a universal, publicly financed system.

We were able to adjust for several sociodemographic and health status characteristics that could explain disparities in rates of use. After these adjustments, we found that contact with general practitioners was higher among members of minorities than among white people. This suggests that despite known barriers such as language and cultural attitudes toward Western medicine, ${ }^{22,23}$ minority members are able to make use of primary care providers at least as well as white people.

A visit to a family physician is most often initiated by the patient; seeing a specialist, however, usually requires a referral from the family physician. If there were biases against minorities, we would expect to have seen a lower rate of visits to specialists. After adjusting for patient characteristics, we found no difference in the proportion of minorities and white people who saw a specialist physician.

Minorities were less likely than white people to be admitted to hospital. The lower admission rate might have been because of better health in the minority groups (i.e., our ability to adjust for severity of disease and urgency of treatment required may have been insufficient) or cultural differences in attitudes toward hospital admission. In our study, $8 \mathrm{I} \%$ of members of visible minorities were immigrants. New immigrants tend to be healthy, but their health status declines as their length of residence in Canada increases. ${ }^{24-30}$ We found that members of visible minorities who reported a longer duration in Canada also reported using health services more frequently. However, among people born in Canada, health service use was slightly less frequent among members of visible minorities than among white people. This finding suggests that the disparity in utilization is not completely explained by acculturation alone.

This study has limitations. First, the CCHS survey collec-

Table 1: Odds ratios for the utilization of health services by members of visible minorities compared with white people

\begin{tabular}{lcc}
\hline \multirow{2}{*}{$\begin{array}{l}\text { Health service } \\
\text { (sex and age, yr) }\end{array}$} & \multicolumn{2}{c}{ Odds ratios $(95 \% \mathrm{Cl})$} \\
\cline { 2 - 3 } & Unadjusted & Adjusted* \\
\hline General practitioner & $1.00(0.96-1.04)$ & $1.28(1.14-1.42)$ \\
Specialist physician & $0.77(0.75-0.80)$ & $1.01(0.93-1.10)$ \\
Hospital admission & $0.65(0.60-0.70)$ & $0.83(0.70-0.98)$ \\
PSA blood test (men $\geq 40)$ & $0.54(0.50-0.59)$ & $0.64(0.52-0.79)$ \\
Mammogram (women $\geq 35)$ & $0.61(0.57-0.65)$ & $0.68(0.59-0.80)$ \\
Pap smear (women $\geq 18)$ & $0.31(0.29-0.33)$ & $0.47(0.39-0.56)$ \\
\hline
\end{tabular}

Note: $\mathrm{Cl}=$ confidence interval, $\mathrm{PSA}=$ prostate-specific antigen.

*Adjusted for sex, age $(<65 \mathrm{yr}$ or $\geq 65 \mathrm{yr}$ ), marital status (married or commonlaw; single: others, including widowed, separated and divorced), highest level of education (less than secondary, secondary, postsecondary), annual income ( $<\$ 30000, \$ 30000-\$ 49999, \$ 50000-\$ 79999, \geq \$ 80000$, datum missing), immigrant status and length of stay in Canada (born in Canada, $<10 \mathrm{yr}$ or $\geq 10 \mathrm{yr}$ since immigration), speaking English or French (yes or no), selfperceived health (excellent, very good, good, fair, poor) and number of chronic diseases $(0,1,2$ or $\geq 3)$. Immigrant status and length of residence in Canada are proxies of acculturation. After categorizing the study population based on immigration status (born in Canada: yes or no), we then grouped those not born in Canada into 2 subgroups ( $<10 \mathrm{yr}$ or $\geq 10 \mathrm{yr}$ since immigration); 1 variable therefore has 3 categories (born in Canada and $<10 \mathrm{yr}$ or $\geq 10 \mathrm{yr}$ since immigration). In our actual modelling, we specified this 3 -level variable by entering 2 yes-or-no dummy variables (immigration $<10 \mathrm{yr}$ ago and $\geq 10 \mathrm{yr}$ ago) into our model; being born in Canada (or not) was the baseline variable. 
ted self-reported use of health services, so its results are subject to recall bias. There is some evidence that respondents tend to overestimate their use of health services; however, this might not vary by ethnicity. ${ }^{31,32}$ The reported rates of use may therefore be higher than actual usage. Second, although the CCHS collected data with use of several languages, people with a language barrier were nevertheless less likely to be surveyed. This selection bias might lead to overestimates of the level of health service use among members of visible minorities, since language barriers can themselves lead to lower use of services. Third, nearly all members of visible minorities (in our sample, $98.3 \%$ ) lived in large cities. ${ }^{18}$ In our risk adjustment, we could not control for geographic location and so would tend to overestimate the odds of use by visible minorities compared with those by white people.

In conclusion, there was no evidence of disparities in rates of contact with physicians, both general practitioners and specialists, between members of visible minorities and white people, but minority members used hospitals less frequently than white people did. The lower rates of hospital admission may be because members of minorities, particularly recent immigrants, are healthier, though there may be unrecognized barriers to hospital utilization. As found in other studies ${ }^{10,15,33-40}$ members of visible minorities underwent cancer screening tests less often than white people did. This may relate to differences in referral patterns or beliefs about cancer screening across ethnicities. Our preliminary analysis of individual ethnicity subgroups, meanwhile, showed that certain subgroups (e.g., people of Japanese and Korean extraction) used general practitioners and specialists less frequently than white people did. Further studies are needed to explore the factors underlying such differences across ethnicities and if it is associated with altered health outcomes.

\section{This article has been peer reviewed.}

From the Departments of Community Health Sciences (Quan, Fong, De Coster, Wang, Noseworthy, Ghali), Psychiatry (Wang) and Medicine (Ghali) and The Centre for Health and Policy Studies (Quan, Noseworthy, Ghali), University of Calgary, and the Calgary Health Region (Musto), Calgary, Alta., and the Manitoba Centre for Health Policy (De Coster), Community Health Sciences, University of Manitoba, Winnipeg, Man.

Competing interests: None declared.

Contributors: Hude Quan developed the concept and design, participated in the analysis and interpretation, and wrote and revised the manuscript. Andrew Fong analyzed and interpreted the data, and edited the initial manuscript. Carolyn De Coster helped with data analysis and interpretation, and drafting and editing of the initial manuscript. Jianli Wang helped data analysis and interpretation, and edited the manuscript. Richard Musto helped with the development of the study design and interpretation of the data, and edited the manuscript. Tom Noseworthy helped development of study design and interpretation of data, and edited the manuscript. William Ghali helped develop the study design and interpret the data and edited the initial manuscript. All authors approved the article in its final form.

Acknowledgements: This study was funded by a Petro-Canada Young Innovator Award given through the University of Calgary. Hude Quan is supported by a Population Health Investigator Award from the Alberta Heritage Foundation for Medical Research, and by a New Investigator Award from the Canadian Institutes of Health Research. William Ghali is supported by a Health Scholar Award from the Alberta Heritage Foundation for Medical Research, and by a Government of Canada Chair in Health Services Research.

\section{Editor's take}

- Racial and ethnic disparities in health and use of health services have been reported in the United States and the United Kingdom. Given the different ethnic composition of the Canadian population and our universal health care system, do similar differences in the use of health and cancer screening services exist in Canada?

- In this study there was no difference in the use of general physician and specialist services between white people and members of visible minorities, but the latter group had less use of hospital and cancer screening services.

Implications for practice: Access to physician services is similar by ethnic groups in Canada. The reasons for the differences in use of hospital and cancer screening services and whether they affect health outcomes by ethnicity need to be further explored.

\section{REFERENCES}

I. Haas JS, Phillips KA, Sonneborn D, et al. Variation in access to health care for different racial/ethnic groups by the racial/ethnic composition of an individual's county of residence. Med Care 2004;42:707-I4.

2. Weinick RM, Zuvekas SH, Cohen JW. Racial and ethnic differences in access to and use of health care services, 1977 to I996. Med Care Res Rev 2000;57(Suppl I):36-54.

3. Sproston KA, Pitson LB, Walker E. The use of primary care services by the Chinese population living in England: examining inequalities. Ethn Health 2001;6:189-96.

4. Yu SM, Huang ZJ, Singh GK. Health status and health services utilization among US Chinese, Asian Indian, Filipino, and other Asian/Pacific Islander children. Pediatrics 2004; II3:IOI-7.

5. Phillips KA, Mayer ML, Aday LA. Barriers to care among racial/ethnic groups under managed care. Health Aff (Millwood) 2000;19:65-75.

6. Mayberry RM, Mili F, Ofili E. Racial and ethnic differences in access to medical care. Med Care Res Rev 2000;57(Suppl I):108-45.

7. Fiscella K, Franks P, Doescher MP, et al. Disparities in health care by race, ethnicity, and language among the insured: findings from a national sample. Med Care 2002;40:52-9.

8. Frisbie WP, Cho Y, Hummer RA. Immigration and the health of Asian and Pacific Islander adults in the United States. Am J Epidemiol 2001;153:372-80.

9. Li PL, Logan S, Yee L, et al. Barriers to meeting the mental health needs of the Chinese community. J Public Health Med I999;2I:74-80.

Io. Hoffman-Goetz L, Breen NL, Meissner H. The impact of social class on the use of cancer screening within three racial/ethnic groups in the United States. Ethn Dis I $998 ; 8: 43-5 \mathrm{I}$.

II. Lee MC. Knowledge, barriers, and motivators related to cervical cancer screening among Korean-American women. A focus group approach. Cancer Nurs 2000;23: I68-75.

I2. Ma GX. Barriers to the use of health services by Chinese Americans. J Allied Health 2000;29:64-70.

I3. Davis SK, Liu Y, Gibbons GH. Disparities in trends of hospitalization for potentially preventable chronic conditions among African Americans during the I99os: implications and benchmarks. Am J Public Health 2003;93:447-55.

I4. Jang M, Lee E, Woo K. Income, language, and citizenship status: factors affecting the health care access and utilization of Chinese Americans. Health Soc Work I998;23:136-45.

I5. Tang TS, Solomon LJ, McCracken LM. Cultural barriers to mammography, clinical breast exam, and breast self-exam among Chinese-American women 60 and older. Prev Med 2000;31:575-83.

I6. Williams DR, Collins C. Racial residential segregation: a fundamental cause of racial disparities in health. Public Health Rep 2001;II6:404-r6.

17. LaVeist TA. Disentangling race and socioeconomic status: a key to understanding health inequalities. JUrban Health 2005;82(2 Suppl 3):iii26-34.

I8. Statistics Canada. I9g6 census: ethnic origin, visible minorities. Ottawa: The Ministry; 1996. Cat no 93 Foo26XDB960oo.

I9. Canada Health Act. I984, c.6, s.I. Available: http://laws.justice.gc.ca/en/c-6/17077 .html (accessed 2006 Feb 9).

20. Statistics Canada. Canadian Community Health Survey (CCHS), cycle I.I, 200I. Available: www.statcan.ca/english/concepts/health (accessed 2006 Jan 30).

21. Phillips KA, Morrison KR, Andersen RR, et al. Understanding the context of healthcare utilization: assessing environmental and provider-related variables in the behavioral model of utilization. Health Serv Res I998;33:57I-96.

22. Williams CC. Increasing access and building equity into mental health services: an 
examination of the potential for change. Can J Commun Ment Health 2001;20:37-51.

23. Smaje C, Grand JL. Ethnicity, equity and the use of health services in the British NHS. Soc Sci Med 1997;45:485-96.

24. Chen J, Ng E, Wilkins R. The health of Canada's immigrants in 1994-95. Health Rep 1996;7:33-45.

25. Dunn JR, Dyck I. Social determinants of health in Canada's immigrant population: results from the National Population Health Survey. Soc Sci Med 2000;51:1573-93.

26. Kopec JA, Williams JI, To T, et al. Cross-cultural comparisons of health status in Canada using the Health Utilities Index. Ethn Health 200I;6:4I-50.

27. Parakulam G, Krishnan V, Odynak D. Health status of Canadian-born and foreignborn residents. Can J Public Health 1992;83:3II-4.

28. Newbold KB, Danforth J. Health status and Canada's immigrant population. Soc Sci Med 2003;57:198I-95.

29. Singh GK, Miller BA. Health, life expectancy, and mortality patterns among immigrant populations in the United States. Can J Public Health 2004;95:Ir4-2I.

3o. Smedley BD, Stith AY, Nelson AR, eds. Unequal Treatment: Confronting Racial and Ethnic Disparities in Health Care. Washington: National Academies Press; 2003.

3I. McPhee SJ, Nguyen TT, Shema SJ, et al. Validation of recall of breast and cervical cancer screening by women in an ethnically diverse population. Prev Med 2002;35:463-73.

32. Reijneveld SA. The cross-cultural validity of self-reported use of health care: a comparison of survey and registration data. J Clin Epidemiol 2000;53:267-72.

33. Yi JK. Factors associated with cervical cancer screening behavior among Vietnamese women. J Community Health 1994;19:189-200.

34. Maxwell AE, Bastani R, Warda US. Demographic predictors of cancer screening among Filipino and Korean immigrants in the United States. Am J Prev Med 2000; 18:62-8.

35. Gilliland FD, Rosenberg RD, Hunt WC, et al. Patterns of mammography use among Hispanic, American Indian, and non-Hispanic white women in New Mexico, 1994-1997. Am J Epidemiol 2000;152:432-7.

36. Wismer BA, Moskowitz JM, Chen AM, et al. Rates and independent correlates of Pap smear testing among Korean-American women. Am J Public Health 1998;88:656-60.

37. Zambrana RE, Breen N, Fox SA, et al. Use of cancer screening practices by Hispanic women: analyses by subgroup. Prev Med I999;29:466-77.

38. Coughlin SS, Uhler RJ. Breast and cervical cancer screening practices among Asian and Pacific Islander women in the United States, I994-I997. Cancer Epidemiol Biomarkers Prev 2000;9:597-603.

39. Coughlin SS, Uhler RJ. Breast and cervical cancer screening practices among Hispanic women in the United States and Puerto Rico, I998-1999. Prev Med 2002;34:242-5I.

40. Maxwell CJ, Bancej CM, Snider J, et al. Factors important in promoting cervica cancer screening among Canadian women: findings from the 1996-97 National Population Health Survey (NPHS). Can J Public Health 2001;92:127-33.

Correspondence to: Dr. Hude Quan, Department of Community

Health Sciences, University of Calgary, 3330 Hospital Dr. NW,

Calgary AB T2N 4NI; fax 403 944-8950; hquan@ucalgary.ca

\section{LEADERSHIP}

$C M A J$ is a founding member of the International Committee of Medical Journal Editors, an organization that is devoted to ensuring the highest integrity in scientific publishing and is a driving force in the mandatory registration of clinical trials. 